\title{
OPEM
}

www.opem.org

Oriental Pharmacy and Experimental Medicine 2010 10(2), 79-85

DOI 10.3742/OPEM.2010.10.2.079

\section{Hepatoprotective and antioxidant activity of the methanolic extract of Mucuna pruriens Bak. roots}

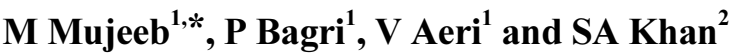 \\ ${ }^{1}$ Department of Pharmacognosy and Phytochemistry, Faculty of Pharmacy, Jamia Hamdard, New Delhi-110062, \\ India; ${ }^{2}$ Department of Pharmacy, Oman Medical College, Muscat, Sultanate of Oman
}

Received for publication August 12, 2008; accepted April 29, 2010

\begin{abstract}
SUMMARY
The methanolic extract of natural roots of Mucuna pruriens was screened for hepatoprotective and antioxidant effects in carbon tetrachloride $\left(\mathrm{CCl}_{4}\right)$ induced hepatotoxicity in Albino rats. The degree of protection was measured by estimating biochemical parameters like serum glutamate oxaloacetate transaminase, serum glutamate pyruvate transaminase, total protein and level of serum bilirubin (both total and direct). The extract also reduced $\mathrm{CCl}_{4}$ induced lipid peroxidation both in-vitro and in-vivo. Hepatoprotective activity of methanolic extract at dose $300 \mathrm{mg} / \mathrm{kg}$ body weight, i.p., was comparable with standard drug Silymarin $(25 \mathrm{mg} / \mathrm{kg}$, i.p.). Furthermore, histopathological experiments were also carried out to support the study.
\end{abstract}

Key words: Mucuna pruriens; Hepatoprotective activity; Antioxidant activity; Carbon tetrachloride

\section{INTRODUCTION}

Mucuna pruriens Bak. (Family; Leguminosae) commonly known as Kiwanch in Hindi, is an annual twining herbaceous plant distributed throughout India in all plain districts to lower subtropical hills of Himalaya (Anonymous, 1995). The plant has been reported to contain 3,4 dihydroxy phenylalanine, alkaloids viz. nicotine, pruriene and prurienidine (Majumdar and Zalani, 1953; Niranjan and Katiyar, 1974), sterols, triterpenes and flavonoids (Aruna et al., 1998).

In Ayurveda (An Indian Traditional system of medicine), the roots of Mucuna pruriens (MP) have been used in treatment of cholera, infertility,

${ }^{*}$ Correspondence: M Mujeeb, Department of Pharmacognosy and Phytochemistry, Faculty of Pharmacy, Jamia Hamdard, New Delhi-110062, India. E-mail: mujueeb_zaidi@yahoo.co.in, shahalamkhan@yahoo.com snakebite and in worm infection (Anonymous, 1995). The other reported activities include Analgesic and Antipyretic (Jauk et al., 1993), anticoagulant (Houghton and Shari., 1994), Antispasmodic (Dhar et al., 1968) and Hypoglycaemic activity (Rathi, 2002). In-vitro lipid peroxidation and antimicrobial activity of MP seeds have also been reported (Yerra et al., 2005).

Keeping in view the role of sterols, flavonoids and triterpens in medicinal plants as hepatoprotective drugs (Handa and Kaur, 1996), it was thought worthwhile to conduct hepatoprotective studies on the roots of MP in scientific manner to validate its use in traditional system of medicine.

\section{MATERIALS AND METHODS}

\section{Plant material}

Roots of MP were procured from Baraut, U.P., 
India and authenticated by the taxonomist of Department of Botany, Faculty of Science, Hamdard University. The voucher specimen was deposited in the herbarium of university for future reference (JHFP-2075).

\section{Preparation of extract}

The air-dried and coarsely powdered roots of plant $(3 \mathrm{~kg})$ were soxhlet extracted with methanol for $72 \mathrm{~h}$. The methanol extract was concentrated on a water bath and dried under reduced pressure to get a dark brown mass (200 g).

High performance thin layer chromatography (HPTLC) fingerprinting and preliminary phytochemical screening

Methanol extract of plant roots $(1 \mathrm{~g} / \mathrm{ml})$ was applied $(2 \mu \mathrm{l})$ on silica gel $\mathrm{G} \mathrm{F}_{254}$ HPTLC plate in duplicate with bandwidth of $5 \mathrm{~mm}$ using Linomat $\mathrm{V}$ applicating device. The chromatogram was developed in Twin trough chamber using solvent system Toluene: Ether (1:1) saturated with $10 \%$ acetic acid and scanned in scanner III at $366 \mathrm{~nm}$ wavelength using mercury lamp in fluorescence mode. On preliminary phytochemical screening of roots of MP, extract showed positive tests for glycosides, steroids, alkaloids and flavonoids.

\section{Determination of phenolic compounds}

Total phenols were estimated by Folin-Ciocalteu reagent according to the method of Gao et al. (2000). The total content was expressed as $\mathrm{mg}$ of Gallic acid equivalents/g extract.

\section{Determinaton of total flavonoids}

Total flavonoid content was estimated according to the Kosalec et al. (2004). The total content was expressed as mg of quercetin equivalents/g extract.

\section{Animals}

The hepatoprotective activity was carried out on Wistar Albino rats of either sex weighing (120 - 150 g), supplied by Central animal house facility of
Jamia Hamdard, New Delhi (Registration no. 173 / CPCSEA). They were maintained in a $12 \mathrm{~h}$ light/ dark cycle at $25 \pm 2^{\circ} \mathrm{C}$ and were allowed free access to standard pellet diet (Amrut Laboratory Rat Feed, Navamaharashtra, Pune, India) and water ad libitum. The study was approved by ethics committee CPCSEA and ethical norms were strictly followed during all experimental procedures.

\section{Experimental protocol}

Animals were divided into five groups; Group I (control), Group II ( $\mathrm{CCl}_{4}$ treated), Group III $\left(\mathrm{CCl}_{4}+\right.$ Silymarin treated), Group IV and V $\left(\mathrm{CCl}_{4}+\right.$ extract). Animals of group II, III, IV and V were administered $50 \%(\mathrm{v} / \mathrm{v}) \mathrm{CCl}_{4}$ in olive oil at a single dose of $2 \mathrm{ml} /$ $\mathrm{kg}$ body weight per day for 4 days by S.C. route. Simultaneously but at different hours of the day, animals of group III, IV and V were fed with Silymarin suspension $(25 \mathrm{mg} / \mathrm{kg}$ body weight, i.p.), methanol extract at a dose of $200 \mathrm{mg} / \mathrm{kg}$ and $300 \mathrm{mg} / \mathrm{kg}$ body weight, i.p. for 4 days respectively. Animals of group I was given distilled water in a volume of $10-\mathrm{ml} / \mathrm{kg}$-body weight.

\section{Serum analysis and histopathological examination} On $5^{\text {th }}$ day, after treatment period the animals of all groups were anaesthetized with ether and sacrificed. Blood was withdrawn from heart and serum was separated by centrifugation at 3,000 rpm at $30^{\circ} \mathrm{C}$ for $15 \mathrm{~min}$ and analysed for various biochemical parameters; Serum transaminases viz. Serum glutamate oxaloacetate transaminase (SGOT) (Frankel and Rietman, 1957), serum glutamate pyruvate transaminase (SGPT) (Frankel and Rietman, 1957), Total protein and Bilirubin (direct and total) (Evelyn and Malloy, 1937). The histopathological studies were also carried out by reported method (Luna, 2002). Liver was removed from sacrificed animal, sliced, and washed in normal saline. Liver pieces were processed in $10 \%$ formaldehyde solution. The pieces of liver were processed and embedded in paraffin wax. Sections made were 4-6 $\mu \mathrm{m}$ in thickness. They 
were stained with hematoxylin and eosin and lastly photographed.

\section{In- vitro antioxidant activity by DPPH method}

The stable 1, 1-diphenyl-2-picryl hydrazyl radical (DPPH) $(75 \mu \mathrm{M})$ was used for determination of free radical-scavenging activity of the extract (Blois, 1958). $2.95 \mathrm{mg}$ of DPPH was dissolved in $100 \mathrm{ml}$ of methanol to give $75 \mu \mathrm{M}$ of DPPH solution.

The methanolic solution $(0.5 \mathrm{ml})$ of plant extract in different concentration was mixed in a test tube with $2.5 \mathrm{ml}$ of methanol containing $75 \mu \mathrm{M} \mathrm{DPPH}$, (stable free radical) which gave a distinctive absorbance at $517 \mathrm{~nm}$. The reaction mixture was set-aside in the dark at room temperature for $90 \mathrm{~min}$, and then absorbance was recorded at $517 \mathrm{~nm}$. The corresponding blank readings were also taken and the remaining DPPH was calculated. The experiment was repeated for three times. Ascorbic acid and quercetin were used as standard controls.

\section{In- vivo antioxidant activity}

The in-vivo antioxidant activity of methanolic extract was carried out in $\mathrm{CCl}_{4}$ intoxicated rats. The liver sample collected were washed with chilled normal saline, weighed and $10 \%(\mathrm{w} / \mathrm{v})$ liver homogenate were made in ice cold $0.15 \mathrm{M} \mathrm{KCl}$ solution using motor driven Teflon pestle. The suspension was centrifuged at $2000 \mathrm{rpm}$ at $4^{\circ} \mathrm{C}$ for $10 \mathrm{~min}$ and clear supernatant was used for the estimation of the following antioxidant markers.

\section{Estimation of liver TBARS}

The measurement of Thiobarbituric acid reactive substances (TBARS) was done as an index of lipid peroxidation and measured in terms of malondialdehyde (MDA) content following the method of Ohkawa et al (1979). The values of TBARS were presented as nmol MDA / mg protein.

\section{Estimation of reduced glutathione (GSH)}

Reduced Glutathione was estimated spectrophotometrically by using Ellman's reagent (5,5-dithiobis-2- nitrobenzoic acid) (Ellman, 1959). Equal quantity of homogenate(W/V) and 10\% trichloroacetic acid were mixed and centrifuged to separate the proteins. To $0.01 \mathrm{ml}$ of this supernatant, $2 \mathrm{ml}$ of phosphate buffer ( $\mathrm{pH} 7.4), 0.5 \mathrm{ml}$ of 5, 5-dithiobisnitro benzoic acid (DTNB) and $0.4 \mathrm{ml}$ of distilled water was added. Absorbance was measured at $412 \mathrm{~nm}$, and the values were expressed as $\mu \mathrm{mol} / \mathrm{g}$ of liver tissue.

\section{Statistical analysis}

Results of biochemical parameters are reported as mean \pm S.E.M. Statistical significance was determined by one way analysis of variance (ANOVA) followed by Dunnet's ' $t$ ' test (Woolson, 1987). $P$ value $<0.05$ was considered statistically significant.

\section{RESULTS}

HPTLC fingerprints of methanolic extract of MP roots showed presence of 18 spots, confirming the presence of different class of phytoconstituents as revealed by preliminary phytochemical screening. Total content of Phenolic and Flavonoid was also determined. The total phenolic and total flavonoid content was found to be $118 \pm 8.8 \mathrm{mg}$ (Gallic acid equivalent/g extract) and $52.81 \pm 1.8 \mathrm{mg}$ (Quercetin equivalent/g extract), respectively.

Administration of $\mathrm{CCl}_{4}$ led to significant hepatocellular damage as evident from increase in serum activities of SGOT, SGPT and bilirubin concentration as compared to normal control group. Treatment of rats with methanolic extract of roots at a dose of $200 \mathrm{mg} / \mathrm{kg}$ and $300 \mathrm{mg} / \mathrm{kg}$ body weight, i.p. exhibited significant reduction $(P<$ 0.05) in $\mathrm{CCl}_{4}$ induced elevation of SGOT, SGPT, bilirubin and increased the level of TP (Total Protein) (Table 1). Treatment with Silymarin also reversed the hepatotoxicity significantly. However extract at a high dose (300 mg/ $\mathrm{kg}$ body weight) produced better protection.

The $\mathrm{IC}_{50}$ of the methanolic extract was found to be $64 \mu \mathrm{g} / \mathrm{ml}$. The value was found to be comparable to that of standard ascorbic acid and quercetin. In 
Table 1. Effects of methanolic extract of $M$. pruriens roots on SGOT, SGPT, TP, Bilirubin in $\mathrm{CCl}_{4}$ induced hepatotoxicity in rats

\begin{tabular}{|c|c|c|c|c|c|}
\hline \multirow{2}{*}{ Group Treatment } & \multirow{2}{*}{$\begin{array}{l}\text { SGOT } \\
(\mathrm{U} / \mathrm{ml})\end{array}$} & \multirow{2}{*}{$\begin{array}{l}\text { SGPT } \\
(\mathrm{U} / \mathrm{ml})\end{array}$} & \multicolumn{2}{|c|}{ Bilirubin (mg/dl) } & \multirow{2}{*}{$\begin{array}{c}\mathrm{TP} \\
(\mathrm{g} / \mathrm{dl})\end{array}$} \\
\hline & & & Total & Direct & \\
\hline I Control & $46.23 \pm 4.28$ & $34 \pm 2.38$ & $0.68 \pm 0.3$ & $0.2 \pm 0.05$ & $7.42 \pm 0.36$ \\
\hline II CCl ${ }_{4}$ treated & $268.39 \pm 9.70$ & $264 \pm 11.01$ & $3.36 \pm 1.50$ & $2.28 \pm 0.19$ & $2.16 \pm 0.25$ \\
\hline III CCl $\mathrm{CC}_{4}+$ Silymarin & $53.06 \pm 3.94^{*}$ & $42.4 \pm 1.43^{*}$ & $1.03 \pm 0.46^{*}$ & $0.37 \pm 0.02^{*}$ & $6.82 \pm 0.48^{*}$ \\
\hline IV CCl ${ }_{4}+$ extract $(200 \mathrm{mg} / \mathrm{Kg})$ & $93.91 \pm 4.25^{*}$ & $105.42 \pm 2.23^{*}$ & $1.61 \pm 0.72^{*}$ & $0.97 \pm 0.11^{*}$ & $4.87 \pm 0.36^{*}$ \\
\hline $\mathrm{V} \mathrm{CCl}_{4}+\operatorname{extract}(300 \mathrm{mg} / \mathrm{Kg})$ & $73.84 \pm 2.54^{*}$ & $80.25 \pm 2.79^{*}$ & $1.28 \pm 0.57^{*}$ & $0.7 \pm 0.13^{*}$ & $5.77 \pm 0.35^{*}$ \\
\hline
\end{tabular}

Values are mean \pm S.E.M. $(\mathrm{n}=5),{ }^{*} \mathrm{P}<0.05 \mathrm{Vs} \mathrm{CCl}_{4}$. one way analysis followed by Dunnet's $t$ test.

Table 2. Effects of methanolic extract of $M$. pruriens roots on TBARS and GSH level in liver tissues of $\mathrm{CCl}_{4}$ intoxicated rats

\begin{tabular}{lcc}
\hline Treatment & TBARS (nmol MDA/mg protein) & GSH (mmol/g liver tissue) \\
\hline Control & $0.87 \pm 0.05$ & $65.45 \pm 8.67$ \\
$\mathrm{CCl}_{4}$ treated & $6.98 \pm 0.53$ & $15.17 \pm 4.34$ \\
$\mathrm{CCl}_{4}+$ Silymarin & $1.21 \pm 0.07^{* *}$ & $64.37 \pm 7.88^{* *}$ \\
$\mathrm{CCl}_{4}+$ extract $(200 \mathrm{mg} / \mathrm{Kg})$ & $4.33 \pm 0.47^{*}$ & $50.88 \pm 6.44^{*}$ \\
$\mathrm{CCl}_{4}+$ extract $(300 \mathrm{mg} / \mathrm{Kg})$ & $1.38 \pm 0.22^{* *}$ & $63.34 \pm 8.36^{* *}$ \\
\hline
\end{tabular}

Values are mean \pm S.E.M. $(\mathrm{n}=5),{ }^{*} P<0.05,{ }^{* *} P<0.001 \mathrm{Vs} \mathrm{CCl}_{4}$. one way analysis followed by Dunnet's $t$ test.

the present study, administration of methanolic extract at dose of 200 and $300 \mathrm{mg} / \mathrm{kg}$ body weight to the $\mathrm{CCl}_{4}$ intoxicated rats caused a significant increase in the level of GSH and a significant decrease in the level of TBARS when compared to $\mathrm{CCl}_{4}$ treated controlled group (Table 2). In liver tissues standard Silymarin at dose $25 \mathrm{mg} / \mathrm{kg}$ also showed significant antioxidant activity. The result of methanolic extract was comparable with that of standard drug Silymarin.

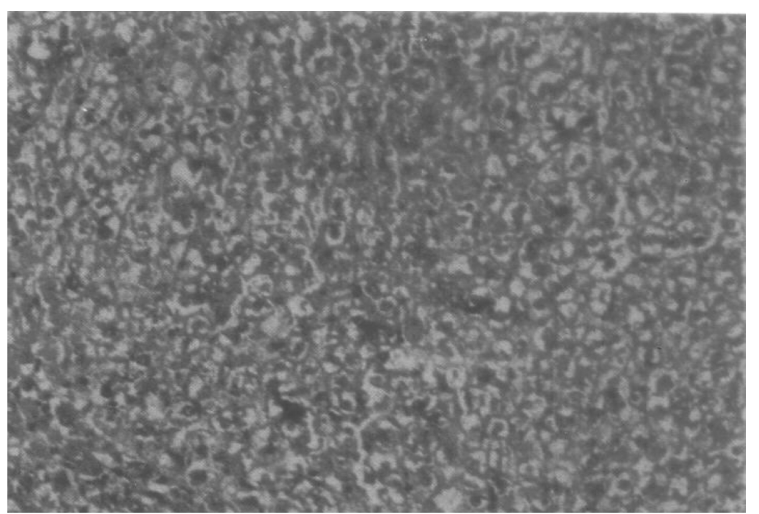

Fig. 1. Liver tissue of control rats showing normal histology.
Histopathological studies of liver sections in control animals showed normal hepatic cells with prominent nucleus and central vein (Fig. 1). In $\mathrm{CCl}_{4}$ treated animals the sections showed hydropic changes in centrilobular hepatocytes with single cell necrosis, congestion of central vein and sinusoids were seen with acute and chronic inflammatory cells mainly in central zone (Fig. 2). Treatment of

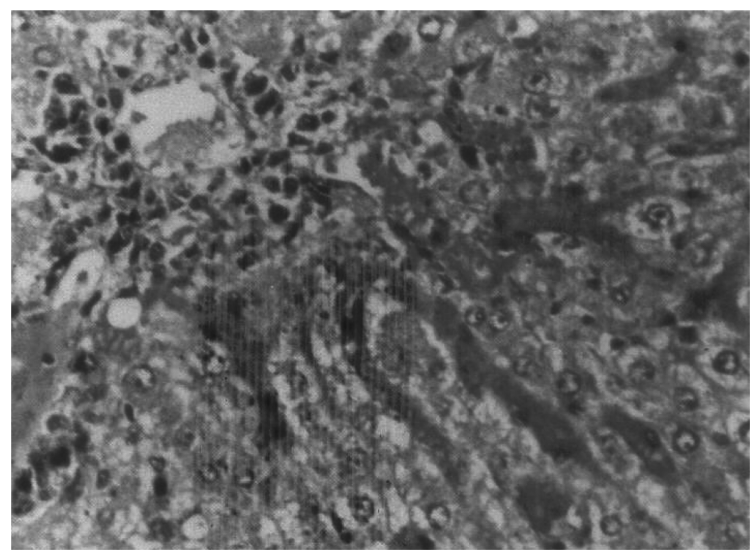

Fig. 2. Liver tissue of $\mathrm{CCl}_{4}$ treated animals showing hydropic changes and acute inflammatory cell infiltrate. 


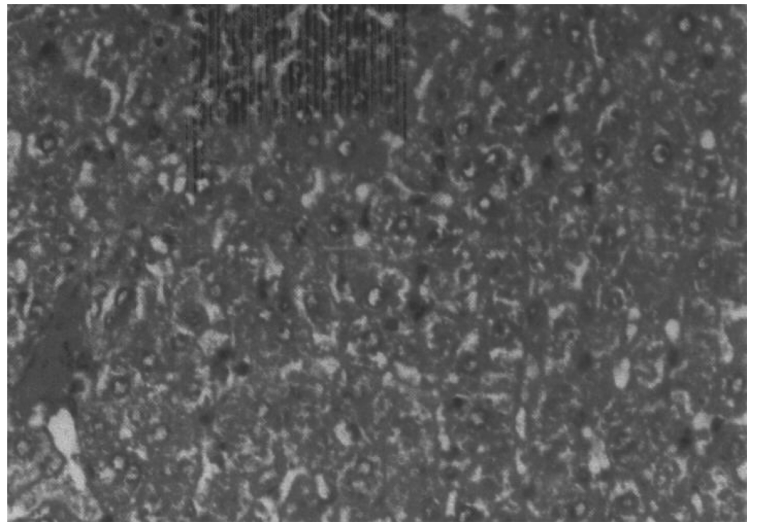

Fig. 3. Liver tissue of rats treated with $\mathrm{CCl}_{4}$ and Silymarin showing almost normal histology.

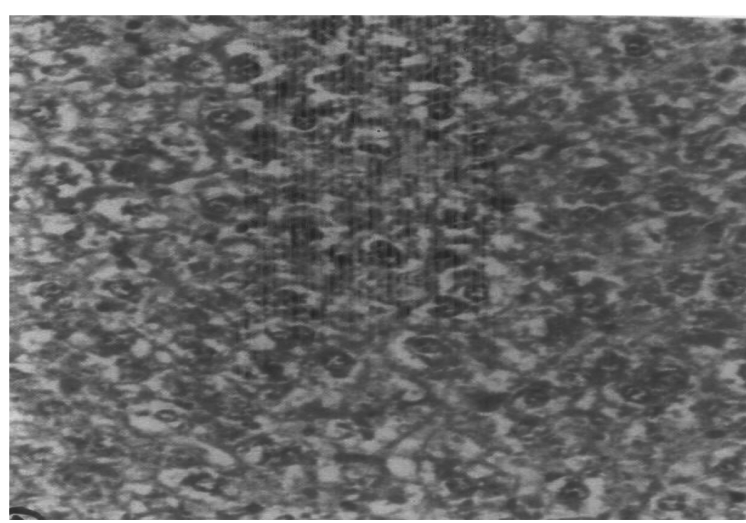

Fig. 4. Liver tissue of rats treated with $\mathrm{CCl}_{4}$ and M. pruriens $(300 \mathrm{mg} / \mathrm{kg})$ showing almost normal histology.

the animals with Silymarin and methanolic extract exhibited a significant recovery of hepatocytes in different sections of the liver (Figs. 3 and 4).

\section{DISCUSSION}

$\mathrm{CCl}_{4}$ is one of the most commonly used hepatotoxin in the experimental study of liver diseases (Johnson and Kroening, 1998). The hepatotoxic effects of $\mathrm{CCl}_{4}$ are largely due to its active metabolite, trichloro methyl radical (Srivastava et al., 1990). These activated radicals bind covalently to the macromolecules and induce peroxidative degradation of membrane lipids of endoplasmic reticulum rich in polyunsaturated fatty acids. This leads to the formation of lipid peroxides, which in turn give products like MDA that cause damage to the membrane. Lipid peroxidative degradation of biomembrane is one of the principle causes of $\mathrm{CCl}_{4}$ toxicity, this is evidenced by the elevation of TBARS and decrease in the activity of free radicals scavenging enzyme (GSH). This is also evidenced by an elevation in the serum marker enzymes. The increase in the levels of serum bilirubin reflected the level of jaundice and increase of transaminases was the clear indication of cellular leakage and loss of functional integrity of cell membrane (Saraswat et al., 1993). Methanolic extract has significantly reduced these liver enzyme levels and has increased the level of total protein in the serum in a dose dependent manner, which indicates hepatoprotection.

The DPPH test is very convenient method for screening small antioxidant molecule because the intensity of reaction can be analysed by simple spectrophotometric method (Soler-Rivas et al., 2000). The DPPH radical is scavenged by antioxidant through the donation of their hydrogen to form the stable radical DPPH molecules. The antioxidant radicals formed are stabilized through the formation of non-radical product.

$\mathrm{IC}_{50}$ is considered to be a good measure of the antioxidant efficiency of pure compound and extract. The $\mathrm{IC}_{50}$ of the methanolic extract of MP roots $(64 \mu \mathrm{g} / \mathrm{ml})$ was found to be comparable to that of standard ascorbic acid and quercetin.

Lipid per-oxidation plays an important role in variety of disease like cancer, diabetes, aging, cardiovascular disorder, hepatitis, rheumatoid arthritis etc.

Lipid peroxidative degradation of biomembrane is one of the principle causes of $\mathrm{CCl}_{4}$ toxicity. This is evidenced by the elevation of TBARS and decrease in the activity of free radicals scavenging enzymes like $\mathrm{GSH}$ in the $\mathrm{CCl}_{4}$ intoxicated animals. Glutathione is a naturrally occurring tripeptide, non-enzymatic biological antioxidant that is abundant in many living creature. It is widely known that a deficiency of GSH within living 
organism can lead to tissue disorder and injury. Liver injury induced by consumption of alcohol and drugs, lung injury by smoking and muscle injury by intense physical activity (Kurata et al., 1993), all are known to be correlated with decreased tissue level of GSH.

The increase in MDA level in liver induced by $\mathrm{CCl}_{4}$ suggests enhanced lipid peroxidation leading to the tissue damage and failure of antioxidant defense mechanism to prevent formation of excessive free radicals. Treatment with methanolic extract (200 and $300 \mathrm{mg} / \mathrm{kg}$ ) reduced the elevated level of TBARS (Thobarbituric acid reactive substances) in $\mathrm{CCl}_{4}$ intoxicated liver tissues. It was also observed that GSH depletion due to the $\mathrm{CCl}_{4}$ challenge was reversed by the test extract.

Histopathological studies revealed that $\mathrm{CCl}_{4}$ caused steatosis and hydropic degeneration of the liver tissue. MP treatment exhibited protection, which confirmed the result of biochemical studies. Also all the effects of methanolic extract of MP were comparable with those of Silymarin, a proven hepatoprotective drug.

Preliminary phytochemical screening indicated the presence of phenolic and flavonoid glycosides. Free radical mediated process has been implicated in the pathogenesis of different diseases. Thus the antioxidant activity of the methanolic extract may be due to the presence of flavonoid and phenolic compounds and hepatoprotective activity is attributed due to its antioxidant property. Further isolation of active principles responsible for its hepatoprotective activity is currently under progress in our lab.

\section{ACKNOWLEDGEMENTS}

The authors are thankful to the Head, Department of Pharmacognosy and Phytochemistry for providing the necessary facilities to carry out the research work.

\section{REFERENCES}

Anonymous. (1995) The Wealth of India. Volume VI, pp. 442-444, National Institute of Science and Communication ,CSIR, New Delhi, India.

Aruna V, Naidu KG, Satyanarayana T, Ganapaty S. (1998) Phytochemical studies on the roots of Mucuna pruriens Baker. Indian drugs, 35, 356-358.

Blois M. (1958) Antioxidant determinations by the use of stable free radicals. Nature, 26, 1199-2000.

Dhar ML, Dhar MM, Mehrotra BN, Ray C. (1968) Screening of Indian plants for biological activity part 1. Indian J. Exp. Biol. 6, 232-247.

Ellman GL. (1959) Tissue sulphydryl groups. Arch Biochem Biophys. 82, 70-77.

Gao X, Ohlander M, Jeppsson N, Bjork L, Trajkovski V. (2000) Changes in antioxidant effects and their relationship to phytonutrients in fruits of sea buckthorn (Hippophae rhamnoides L.) during maturation. J. Agricultural Food Chem. 48, 1485-1490.

Handa SS, Kaur MK. (1996) Supplement to cultivation and utilization of medicinal plants. 2, 63-64.

Houghton PJ, Shari KP. (1994) The effect on blood clotting of some West African plants used against snakebite. J. Ethnopharmacology, 44, 99-108.

Jauk L, Galati EM, Kirjavainen S, Forestieri AM, Tovata A. (1993) Analgesic and antipyretic effects of Mucuna prureins. Int. J. Pharmacognosy, 37, 213-216.

Johnson DE, Kroening C. (1998) Mechanism of early Carbon tetrachloride toxicity in cultured rat hepatocytes. Pharmacol. Toxicol. 83, 231-239.

Kosalec I, Bakmaz M, Repeliniak S, Vladimirknezevic S. (2004) Quantitative analysis of the flavonoids in raw propolis from northern Croatia. Acta Pharmaceutica 54, 65-72.

Kurata M, Suzuki M, Agar MS. (1993) Antioxidant system and erythrocyte life span in mammals. Biochem Physiol. 106, 477-487.

Luna LG. (2002) Manual of histology; staining methods of Armed Force Institute of Pathology, $3^{\text {rd }}$ Ed, Mc Graw Hill Book Co. Ltd.

Majumdar DN, Zalani CD. (1953) Mucuna pruriens DC, Alkaloidal constituents III, isolation of water soluble alkaloids and a study of their chemical and physiological characterization. Indian J. Pharm. 5, 62-65.

Malloy HT, Evelyn KA. (1937) The determination of bilirubin with the photometric colorimeter. J. Biol. Chem. 119, 481-490.

Niranjan GS, Katiyar SK. (1974) Chemical composition of some legumes. J. Indian Chem. Soc.56, 872-877. 
Ohkawa H, Onishi N, Yagi K. (1979) Assay of lipid peroxidation in animal tissue by thiobarbituric acid reaction. Anal Biochem. 95, 351-358.

Rathi SS. (2002) The effect of Memordica charantia and Mucuna pruriens in experimental diabetes and on key metabolising enzymes involved in carbohydrate metabolism. Phytother. Res. 16, 236-243.

RietmanS, Frankel S. (1957) A colorimetric determination of serum glutamic oxaloacetic and glutamic pyruvic transaminases. Am. J. Clin. Pathol. 28, 56-63.

Saraswat B, Visen PK, Patnaik GK, Dhawan BN. (1993) Anticholestastic effect of Picroliv, active hepatoprotective principle of Picrorhiza kurroa against $\mathrm{CCl}_{4}$ induced cholestasis. India J. Exp. Biol. 31, 316-318.

Soler- Rivas C, Espin JC, Wicker HJ. (2000) An easy and fast test to compare total free radicals scavenger capacity of total food stuffs. Phytochemical Analysis 11, 1-9.

Srivastava SP, Chen NO, Hotlzman JL. (1990) The in vitro NADPH dependant inhibition by $\mathrm{CCl}_{4}$ of the ATP dependant Calcium uptake of hepatic microsomes from male rats. Studies on the mechanism o inactivation of the hepatic microsomal calcium pump by $\mathrm{CCl}_{3}$ radical. J. Biol. Chem. 265, 8392-8399. Woolson RF. (1987) Statistical methods for the analysis of biomedical data. John Wiley and Sons Inc. New York.

Yerra R, Malaya G, Mazumder UK. (2005) In Vitro lipid peroxidation and antimicrobial activity of Mucuna pruriens seeds. Iranian Journal of Pharmacology and Therapeutics 4, 32-35. 